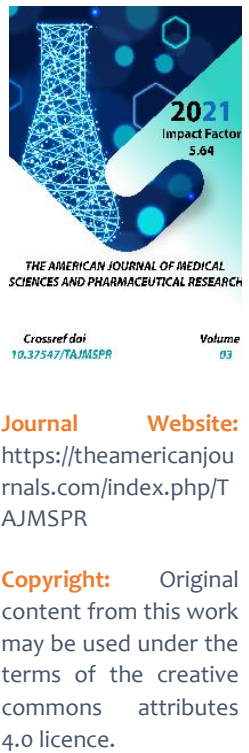

\section{Microscopic Examination Of Postcapillary Cerebral Venues In Hemorrhagic Stroke}

Khaidarov Nodir Kadyrovich

Department Of Nervous Diseases And Physiotherapy, Tashkent State Institute Of Dentistry, Tashkent, Uzbekistan

Shomurodov Kahramon Erkinovich

Department Of Oral And Maxillofacial Diseases And Injuries, Tashkent State Dental Institute, Tashkent, Uzbekistan

Kamalova Malika Ilhomovna

Department Of Human Anatomy, Samarkand State Medical Institute, Samarkand, Uzbekistan

\title{
ABSTRACT
}

Hemorrhagic stroke among acute cerebral circulatory disorders is characterized by severe neurological complications and the need to choose between surgical intervention or therapeutic therapy. According to the World Health Organization (WHO)". Globally, stroke deaths will reach 7.8 million by 2030 unless an aggressive global response to the epidemic is put in place" 1 . Subarachnoid haemorrhage, which accounts for half of the non-traumatic intracerebral haemorrhage, affects the most active and able-bodied population. The most important medical and social objectives are to monitor the course of the disease from the first hours after the onset of stroke, to prescribe adequate treatment in a timely manner, and to reduce mortality and disability rates $[5,9]$.

\section{KEYWORDS}

Cerebral circulation disorder, atherosclerosis, stroke, cerebral brain.

\section{INTRODUCTION}

One of the leading causes of stroke is commonly considered to be vascular wall failure and related main vessel thrombosis, occlusions, and embolisms. Despite certain advances in modern neuroimaging techniques and major advances in the study of the pathogenetic components of the clinical picture of modern stroke, certain pathomorphological aspects of the development of cerebral vascular ischaemia have not been sufficiently investigated $[1,3]$. The pathological anatomy of cerebral circulation disorders is very complex due to the variety of forms of circulatory disorders in the brain and the immediate mechanisms of their development. The severity of brain damage, in 
this case, varies in a wide range - from subtle changes in the individual structural elements of the nervous tissue and vessels to the formation of foci, often extensive, with gross anatomical destruction of the brain. The cerebral circulation disorder can also lead to less significant focal or diffuse changes in the brain: the appearance of separate areas of perivascular melting (encephalolysis), foci of neuronal prolapse, the focal or diffuse proliferation of astrocytes, etc. [2,6]. The polymorphism of changes in the brain in cerebral circulatory disorders and the diversity of their pathogenesis, in addition to the underlying disease and the background in which they occur, are largely due to the peculiarities of the blood supply and the structure of the central nervous system. The cerebral arterial system has several features that no other human organ has. The brain does not have, like most other organs, "legs" or "gates", in the area of which one major artery enters the organ and already its parenchyma is divided into branches. Blood is delivered to the brain through four major vessels (main arteries of the head): two carotid and two vertebral arteries. At the base of the brain, these four arteries join and form a polygon called the "Circle of Willis". This circle plays a particularly important role in the alignment and redistribution of blood in all circulatory disorders in the basin of any of the main arteries $[2,9,10,11]$. It is also necessary to keep in mind that although the structure of the arterial system as a whole follows the angiogenetic law, there is a known specificity of angioarchitectonics in different parts of the brain (cortex, central white matter, subcortical nodes, brain stem, etc.).

The variety of morphogenesis of brain substance changes in cerebral circulatory disorders is also due to the disturbance of subtle mechanisms of cerebral blood flow autoregulation - brain metabolism, intravascular pressure and nerve regulation. Autoregulation disorder in cerebral circulatory disorders is always present, often determining their occurrence as well as the localization, volume, nature and features of morphological changes in the brain substance $[7,8]$.

Purpose of study: Microscopic examination of postcapillary venules of the brain in haemorrhagic stroke.

\section{MATERIAL AND METHODS}

We studied 30 sectional cases of haemorrhagic stroke. Case histories and protocols of pathological anatomical investigations were studied. The brain was studied after its fixation in formalin solution according to the method adopted by the laboratory of pathological anatomy. The essence was as follows. The brain was examined only on frontal blocks, which helps to determine the location of focal changes in relation to all anatomical formations of the brain and its vascular basins. The brain was removed from the skull in a pathological anatomical manner. The dura mater and its sinuses were examined, followed by the spider web and the brain substance from the surface to detect subarachnoid haemorrhages and infarcts in the cortex. After external examination, the vessels of the base of the brain were examined. Further, for histological examination we took pieces from the border zone of haemorrhage and surrounding cerebral tissue and distant areas of brain tissue, we investigated microscopic examination of the brain, postcapillary venules of the brain in hemorrhagic stroke. Brain pieces were fixed in $10 \%$ neutral formalin for 72 hours, then washed in running water for 3-4 hours. 
Dewaxing was performed from the slices in three portions of xylene for 3-5 min each. Xylene was removed with $1000 \mathrm{C}$ alcohol for 2-3 min. Alcohol was removed from slices by performing alcohols of decreasing strengths, 960 and 700, for 2-3 minutes each, and then placed in distilled water for 1 to 2 minutes. Staining of slices was carried out by hematoxylin and eosin, according to van Gieson methods (determination of collagen fibres and myocytes in vessels), Microscopic methods of examination, staining of micro preparations by hematoxylin and eosin, according to van Gieson methods were carried out.

\section{RESULTS}

The results of microscopic examination of brain tissue in hemorrhagic stroke showed that the main pathomorphological changes are observed in the wall of all vascular components of the MCR. In hemorrhagic stroke, more pronounced damage is observed in postcapillary venules compared to capillaries. Almost all postcapillary venules localised in both the cortex and the medulla are dilated, with a thinning wall and signs of destruction and decay. Perivascular haemorrhage is identified in almost all postcapillary venules. Most cases of haemorrhage were due to rupture of the venular wall (Figure 1), and a smaller number of cases showed diabetic perivascular haemorrhage.

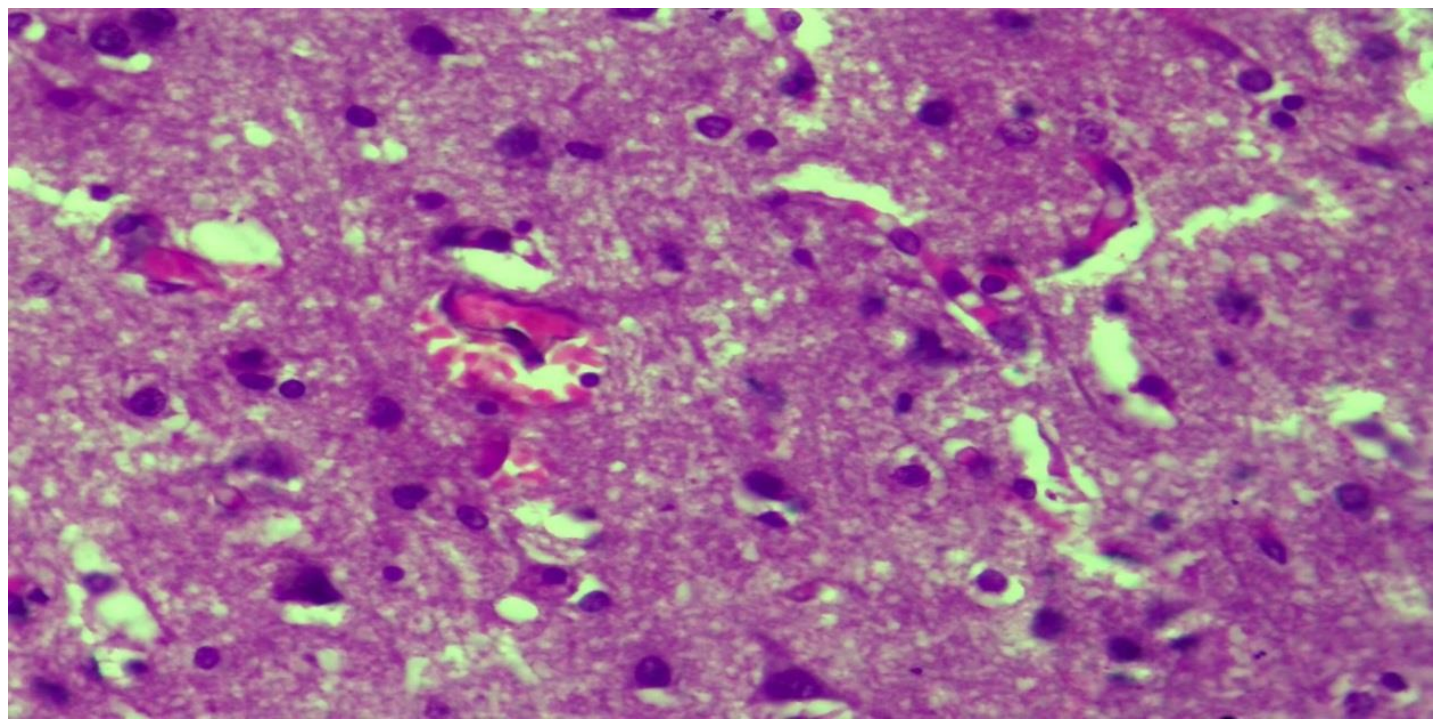

Figure 1. Postcapillary venule rupture with haemorrhage. Staining: G-E. Magnification: 10x40.

In perivascular haemorrhage in the wall of the postcapillary venules, the elastic membranes are loosened, fragmented and form separate clumps, which in histochemical examination by Weigert's method was manifested as the loosening of the grey-silicate fibrillar structures
(Fig. 2). Around the postcapillary venules, the cerebral substance underwent pronounced swelling and loosening with the disintegration of the nerve fibres. 


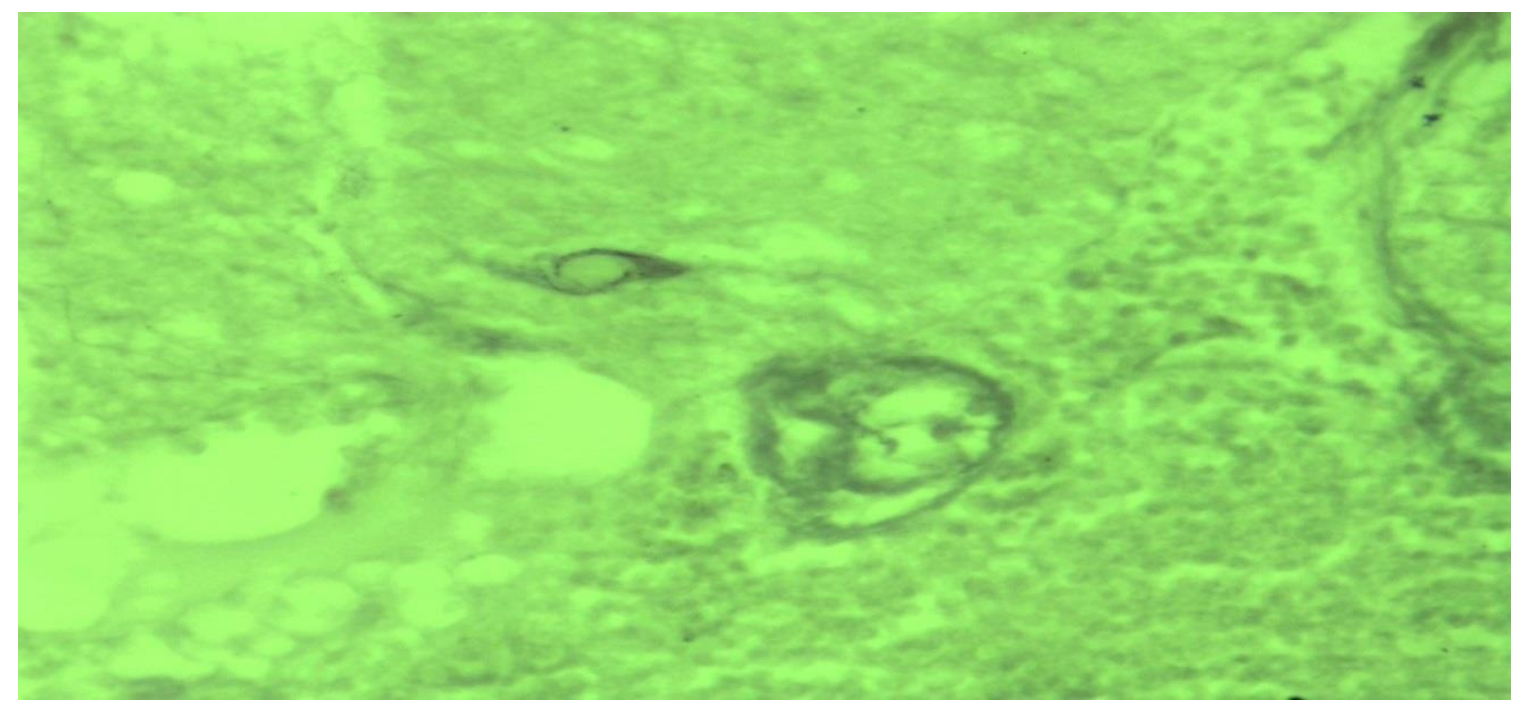

Fig.2.Loosening of elastic fibres in the wall of the postcapillary venule in haemorrhagic stroke. Staining: Weigert's stain. Uv: $10 \times 40$.

Examination of the venous vessels under a high magnification microscope showed that the wall is thin, represented by a basal membrane and flattened endothelial cells. The lumen is always filled with blood, a large edematous cavity is noted in the perivascular space, the adjacent cerebral substance is loosened, crucified with lysis of nerve fibres and karyolysis, karyopycnosis of glial cells.

\section{CONCLUSIONS}

Thus, the peculiarities of microscopic examination of postcapillary venules of the brain in hemorrhagic stroke have been established, at the same time, some peculiarities of their realization have been noted. In particular, changes in the MCR vessels in hemorrhagic stroke, are caused by hypoxia and ischemia of the brain, its oedema, sharp violation of vascular permeability. Pathomorphological changes cover all structural and functional levels of not only the arterial system but also the venous system of the brain.

\section{REFERENCES}

1. Kamalova, M. I., \& Ismoilov, O. I. Morphological changes in the vessels of the microcirculatory system of the brain during hemorrhagic stroke.

2. Ilkhomovna, K. M., Eriyigitovich, I. S., \& Kadyrovich, K. N. (2020). Morphological Features of Microvascular Tissue of The Brain At Hemorrhagic Stroke. The American Journal of Medical Sciences and Pharmaceutical Research, 2(10), 53-59.

3. Ilhomovna, K. M., Kadyrovich, K. N., \& Eryigitovich, I. S. (2021). Patient Demographics in Haemorrhagic and Ischaemic Stroke. Central Asian Journal of Medical and Natural Sciences, 2(4), 40-42.

4. Kamalova, M. I., Eriyigitovich, I. S., \& Khaydarov, N. K. (2020). 
Morfologicheskie izmenenija sosudov golovnogo mozga pri ishemicheskom insul'te [Morphological changes in the vessels of the cerebral cortex during ischemic stroke]. Journal of Biomedicine and Practice, 6 (5). (in Russian).

5. Камалова, М. И., \& Хайдаров, Н. К. (2020). Prevention and risk factors for brain infarction (Literature Review). журнал неврологии и нейрохирургических исследований, 1(2).

6. Malika, K. I., Nodir, H. K., \& Shavkat, I. E. (2020). Modern understanding of risk factors and prevention of brain infarction (literature review). Zhurnal nevrologii i nejrohirurgicheskih issledovanij, 3(1).

7. Vereshchagin, N.V. (2003). Stroke heterogeneity: a clinician's perspective. J. Neurol. and psychiatrist, (9), 8.

8. TOAST Investigators. Low Molecular Weight Heparinoid, ORG 10172 (Danaparoid), and outcome after acute ischaemic stroke. JAMA. 1998; 279: 1265-72.

9. Hart R.G., Diener H.C., Coutts S.B. Embolic strokes of undetermined source: the case for a new clinical construct. Lancet Neurol. 2014; 13: 42938.high-risk individuals: A randomised placebo-controlled trial. Lancet. 2002; 360: 7-22.

10. Muhiddinovna, B. Z. (2020). Functions and forms of chemical experiment. European science review, (1-2), 48-50.

11. Djuraeva, D. D., \& Berdiyeva, Z. M. (2016). Cultural heritage as a factor of human development (on the example of Uzbekistan). Ученый XXI века, 23. 